\title{
Near real-time monitoring of flow velocity and direction in the floating ice tongue of the Shirase Glacier using low-cost GPS buoys
}

\author{
Yuichi Aoyama ${ }^{1}$, Koichiro Doi $^{1}$, Kazuo Shibuya ${ }^{1}$, Harumi Ohta ${ }^{2,3}$, and Iuko Tsuwa ${ }^{2,4}$ \\ ${ }^{1}$ National Institute of Polar Research and SOKENDAI, Tokyo 190-8518, Japan \\ ${ }^{2}$ The $51^{\text {st }}$ Japanese Antarctic Research Expedition, Tokyo 190-8518, Japan \\ ${ }^{3}$ Global Ocean Development Inc., Kanagawa 233-0002, Japan \\ ${ }^{4}$ Institute of Industrial Science, the University of Tokyo, Tokyo 153-8505, Japan
}

(Received November 1, 2011; Revised June 18, 2012; Accepted June 26, 2012; Online published March 6, 2013)

\begin{abstract}
The horizontal velocity vector of ice flow on the floating ice tongue of the Shirase Glacier, East Antarctica, was determined using two GPS buoys located on its east and west sides. The GPS buoys consisted of a singlefrequency GPS receiver module and an Iridium satellite communication system. The instantaneous horizontal position of each GPS buoy was automatically obtained every 30 minutes, and the data were immediately transmitted to the National Institute of Polar Research (NIPR), Tokyo, Japan, via a satellite link. The location data demonstrated that the floating ice tongue moved primarily in a linear manner during the monitoring period between February and April, 2010. The speed and azimuth of the eastern buoy were $(5.779 \pm 0.004 \mathrm{~m} / \mathrm{day}$, $\left.\mathrm{N} 1.4^{\circ} \mathrm{E} \pm 0.5^{\circ}\right)$, respectively, while for the western buoy the speed and azimuth were $(7.005 \pm 0.006 \mathrm{~m} / \mathrm{day}$, $\mathrm{N} 13.1^{\circ} \mathrm{W} \pm 0.6^{\circ}$ ), respectively. Short-term variations about the mean speed and azimuth of the ice flow, with a period of 3-10 days, were also identified.
\end{abstract}

Key words: Single-frequency GPS, ice flow, Shirase Glacier.

\section{Introduction}

The mass balance of the Antarctic ice sheet depends upon changes in ice discharge and snow accumulation, and is related to global sea level rise and the reduction in fresh water storage. Ice discharge and snow accumulation in Antarctica have been evaluated using various measurement techniques (Chen et al., 2006; Velicogna and Wahr, 2006; Rignot et al., 2008, 2011b; Shepherd et al., 2010). For example, the time-variable Earth's gravity field obtained from the GRACE (Gravity Recovery and Climate Experiment) satellite gravity mission was used to determine the mass of ice lost from the Antarctic ice sheet over the last decade (Chen et al., 2006; Velicogna and Wahr, 2006). In addition, a comprehensive and high-resolution map of all of the Antarctic ice flows, which play a dominant role in ice discharge, was produced from interferometric synthetic aperture radar (InSAR) data (Rignot et al., 2011a). These results reveal the loss of ice mass in West Antarctica rather than East Antarctica.

However, in East Antarctica there are ice streams and glaciers causing ice discharge from their drainage basin to the ocean. The Shirase Glacier, located to the south of Lützow-Holmbukta, is the fastest ice stream among them, and this is due to basal sliding (Mae and Naruse, 1978). The Shirase Glacier has three outlets: the main stream, the west tributary, and sheet flow to the west of the glacier (Fujii,

Copyright (C) The Society of Geomagnetism and Earth, Planetary and Space Sciences (SGEPSS); The Seismological Society of Japan; The Volcanological Society of Japan; The Geodetic Society of Japan; The Japanese Society for Planetary Sciences; TERRAPUB.

doi:10.5047/eps.2012.06.011
1981). These outlets form a floating ice tongue composed of a conglomeration of icebergs. The floating ice tongue periodically elongates to a length of about $60 \mathrm{~km}$, but also breaks up completely at intervals of more than a decade. The last breakup occurred during April and May 1998 (see Nakamura et al. (2007b) for synthetic aperture radar (SAR) images of that period). Following this event, the floating ice tongue has grown continuously until the present-day (June 2012) without any further breakup. To clarify the dynamic properties of the ice flow that periodically cause the breakup of the floating ice tongue, and to quantify the ice mass discharge of Shirase Glacier, we carried out direct, continuous, and near real-time monitoring of its current ice flow using low-cost single-frequency GPS. Such GPS measurements have the advantage of allowing ice flow monitoring at a high temporal resolution, but it is more difficult to cover a wide horizontal range. Based on our GPS data, we present here the average velocity vectors of the ice flow, analyze the short-term fluctuations in these vectors, and show that the type of single-frequency GPS technology used here is suitable for monitoring variations in ice flows with periods of less than 10 days.

\section{Monitoring Ice Flow in the Downstream Region of the Shirase Glacier}

\subsection{Measurement system and installation}

We used drifting GPS buoys (ZTB-R6-P1 manufactured by Zeni Lite Buoy Co., Ltd., Tokyo Japan) that consist of a solar panel $(8 \mathrm{~V}, 0.99 \mathrm{~W})$, a Pb battery (6 V, $4.5 \mathrm{Ah})$, a single-frequency code GPS receiver module (including antenna), and an Iridium satellite communication system with 

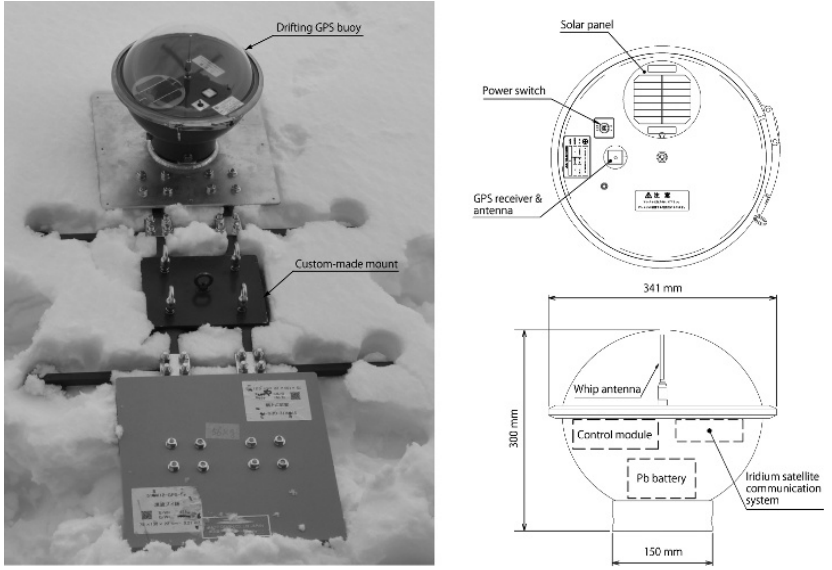

Fig. 1. GPS buoy system installed on the Shirase Glacier. (left) Photo of the drifting GPS buoy (ZTB-R6-P1) mounted on its custom-made $50 \mathrm{~kg}$ base. (right) Plan of ZTB-R6-P1.

a whip antenna, which are built into a spherical shell of $300 \mathrm{~mm}$ in diameter (Fig. 1). The shell is in two parts: a lower hemisphere of aluminum alloy with a protective coating, and an upper hemisphere made of transparent shockresistant resin.

The instantaneous position of the GPS buoys, based on WGS84, was determined by the single-frequency code GPS receiver module at regular intervals, which could be set to between 5 minutes and 24 hours. The GPS module wakes from sleep mode several seconds before each measuring point, and then measures longitude, latitude, and ellipsoidal height five times. These readings are then averaged to determine the instantaneous position of the buoy. The nominal error of the GPS module is ca. $10 \mathrm{~m}$. The longitude and latitude, as well as the battery level of each buoy, were immediately sent to a registered user's host computer system via satellite using the Iridium Short Burst Data Service (SBD). The GPS buoys used in these measurements were originally designed for the monitoring of ocean currents, so the ellipsoidal height was not reported. The SBD allowed us to send and receive small data messages (less than 340 bytes) to anywhere on the Earth's surface. These small data messages, including the instantaneous position and battery level of the GPS buoys, were transmitted to the National Institute of Polar Research (NIPR) server via e-mail. The power consumption of a GPS buoy was $0.846 \mathrm{~mA}$ during positioning and Iridium satellite communication, and $0.6 \mathrm{~mA}$ per hour in sleep mode. The typical daily power consumption was about $0.055 \mathrm{~A}$.

The total weight of a GPS buoy was less than $5 \mathrm{~kg}$, because it was originally developed as a floating device. Its low weight allowed us to fix the buoy to a custom-made mount that was weighed down with $50 \mathrm{~kg}$ of steel (KAIYO DENSHI Co. Ltd., Saitama, Japan) as shown in Fig. 1. This mounting base was necessary to prevent the GPS buoy from moving in strong winds or blizzards, and for ease of installation on the iceberg by helicopter.

The two GPS buoys (serial numbers: 1790 and 8790) were installed on the east, and west, sides of the downstream region of the Shirase Glacier to the south of LützowHolmbukta, East Antarctica (Fig. 2) on 5 February, 2010.

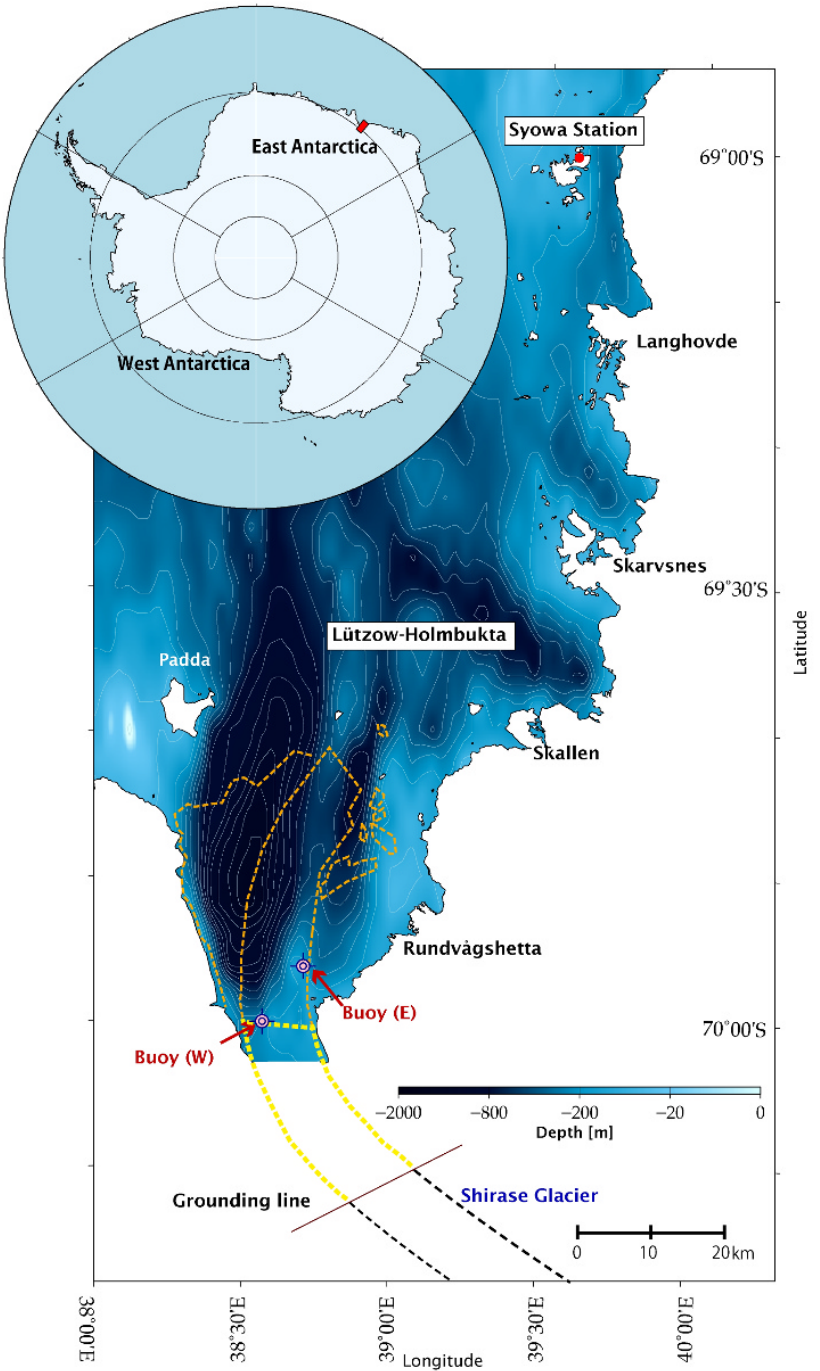

Fig. 2. Location of the monitoring sites and GPS buoys. Bathymetry is based on submarine topography of Lützow-Holmbukta (Moriwaki and Yoshida, 2002) and 2-minute Gridded Global Relief (ETOPO2, National Geophysical Data Center, National Oceanic and Atmospheric Administration, U.S. Dept. of Commerce, http://www.ngdc.noaa.gov/mgg/global/etopo2.html). Yellow and orange dashed lines indicate the position of the floating ice tongue, and the conglomeration of icebergs calving from the floating ice tongue, respectively, which are based on a radar image obtained from the Advanced Land Observing Satellite (ALOS) on 25 July, 2010.

The buoys were carried by helicopter to the installation points and were positioned on the floating ice tongue or the conglomeration of icebergs (Fig. 2). The initial position of GPS buoy 1790 was $69.9378^{\circ} \mathrm{S}, 38.7099^{\circ} \mathrm{E}$, and of buoy 8790 was $70.0013^{\circ} \mathrm{S}, 38.5725^{\circ} \mathrm{E}$ (hereafter, GPS buoys 1790 and 8790 are referred to as GPS buoy (E) and (W), respectively).

\subsection{Data gathered}

The longitude and latitude of the instantaneous position and the battery level of each GPS buoy were automatically delivered to the NIPR server via SBD every 30 minutes, so that continuous and near real-time monitoring of the positions of the GPS buoys was accomplished without any further human intervention following installation. However, the GPS buoys went into sleep mode in April due to low 

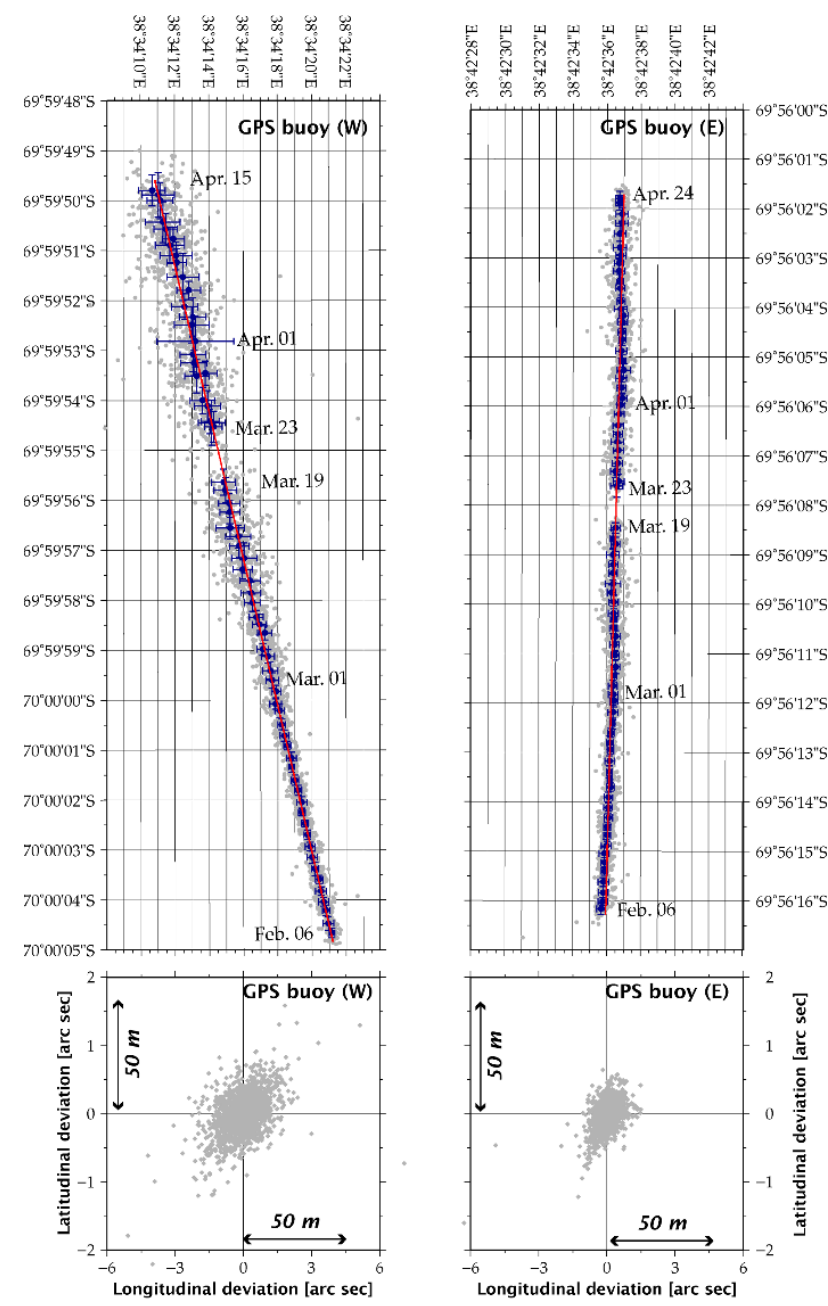

Fig. 3. (top) Instantaneous GPS locations obtained every 30 minutes from GPS buoys (E) and (W) between February and April, 2010. Blue circles with horizontal and vertical error bars denote daily averages with standard deviations. Red straight line fitted by the least squares method to the instantaneous positions. (bottom) Distribution of deviations of instantaneous GPS locations from the straight line.

battery power, and were unable to restart when the following austral summer began. Consequently, the monitoring period of GPS buoy (E) was between 07:30 UT on 5 February, and 00:30 UT on 24 April, 2010, while that of GPS buoy (W) was between 07:00 UT on 5 February, and 06:00 UT on 14 April, 2010. Both GPS buoy datasets were interrupted by a failure of the NIPR mail server between 15:00 and 20:30 UT on 8 March and between 04:30 UT on 19 March and 03:00 UT on 23 March. Observations were also missed on a further four occasions for GPS buoy (E) and once for GPS buoy (W). Instantaneous positions were obtained on 3526 and 3109 occasions, while there were 206 and 202 missing observations for GPS buoys (E) and (W), respectively.

\section{Results}

As expected, the GPS locations obtained from the two buoys, (E) and (W), and their daily averages, followed an approximately linear trend (Fig. 3, top). The time series of the longitude and latitude of both GPS buoys were also roughly linear and their equivalents are shown in Figs. 4(a,

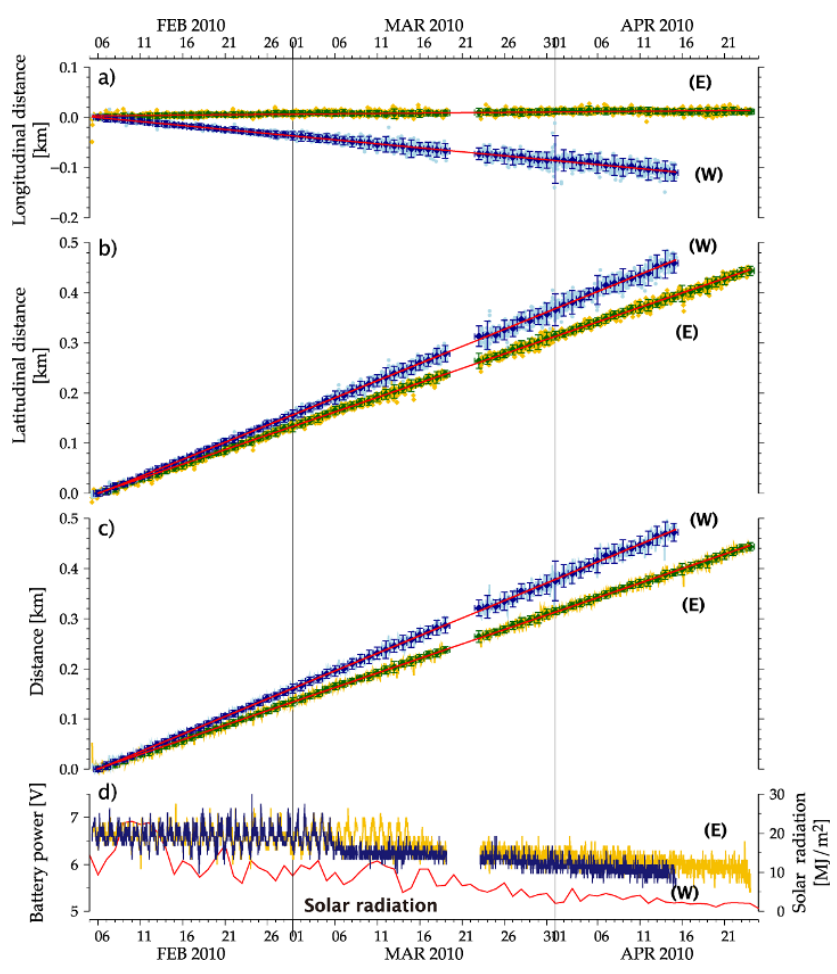

Fig. 4. The time series of (a) longitudinal, (b) latitudinal, and (c) horizontal distances from the starting point on 5 February based on daily averaged locations, and (d) battery power level compared with solar radiation recorded at Syowa Station.

b). Consequently, a straight line was fitted to the time series using the least squares method:

$$
\hat{y}_{k}(t)=a_{k}+b_{k} \times t,
$$

where $a_{k}$ and $b_{k}$ are regression coefficients, $t$ is time, and the subscript $k$ substitutes for the name of a variable. The best fit for both the longitude and latitude time series, $\hat{y}_{\text {lon }}(t)$ and $\hat{y}_{\text {lat }}(t)$, respectively, were combined with the time variable $(t)$ to show the trend of the horizontal displacement of each GPS buoy (red line in Fig. 3, top). These trend lines fall within one standard deviation of the average daily location (Fig. 3, top). This result indicates that the primary direction of movement of the GPS buoys attached to the floating ice tongue remained steady during the monitoring period between February and April, 2010.

To quantify the direction and speed of flow of the floating ice tongue, the geographical coordinates of the 30-minute GPS locations were converted into local horizontal Cartesian coordinates, where each origin was the daily average position of the GPS buoy on 5 February, 2010. We applied the least squares estimate of the regression coefficients in Eq. (1) to the east-west (EW), and north-south (NS), components of the converted positions (Figs. 4(a, b)). Comparing $\hat{y}_{\mathrm{EW}}(t)$ with $\hat{y}_{\mathrm{NS}}(t)$, the NS component dominated the EW component in the data from both GPS buoys. The averaged directions of the ice flow over the observation period corresponding to the azimuths of each straight line in Fig. 3, which were derived from $\tan ^{-1}\left(b_{\mathrm{EW}} / b_{\mathrm{NS}}\right)$, are $\mathrm{N} 1.4^{\circ} \mathrm{E} \pm 0.5^{\circ}$ for GPS buoy (E) and $\mathrm{N} 13.1^{\circ} \mathrm{W} \pm 0.6^{\circ}$ for GPS buoy (W). These results indicate that the floating ice tongue (or the conglomeration of icebergs) associated 
(a)

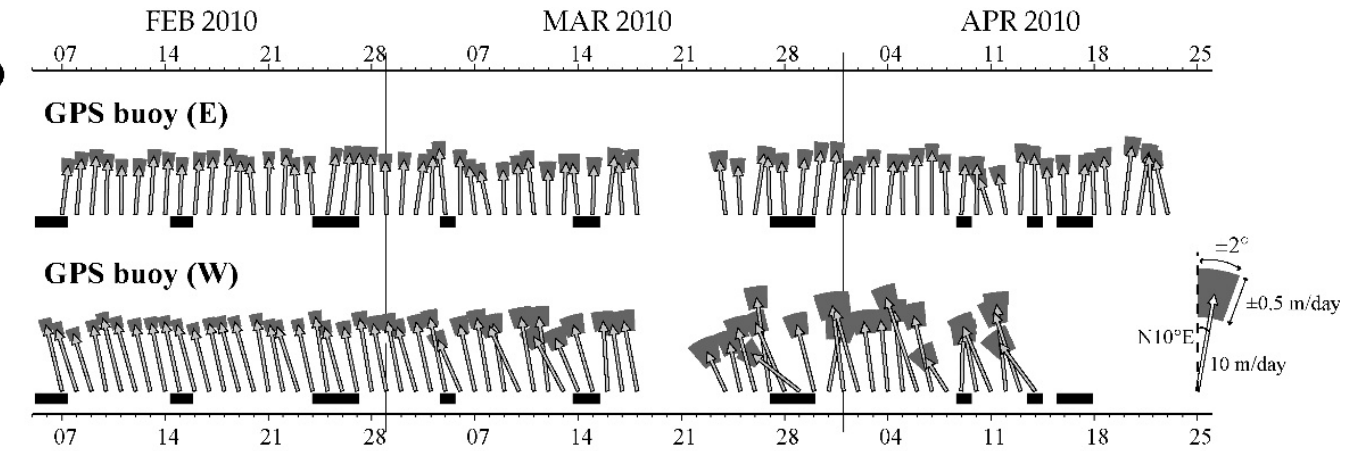

(b)

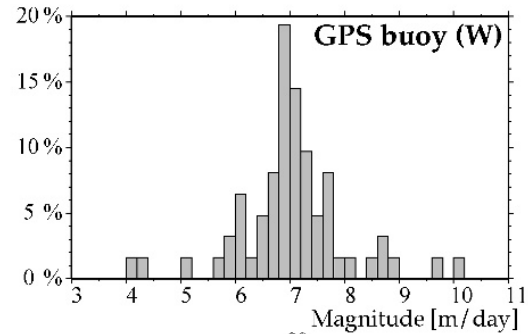

GPS buoy $(\mathrm{W})$

(c)
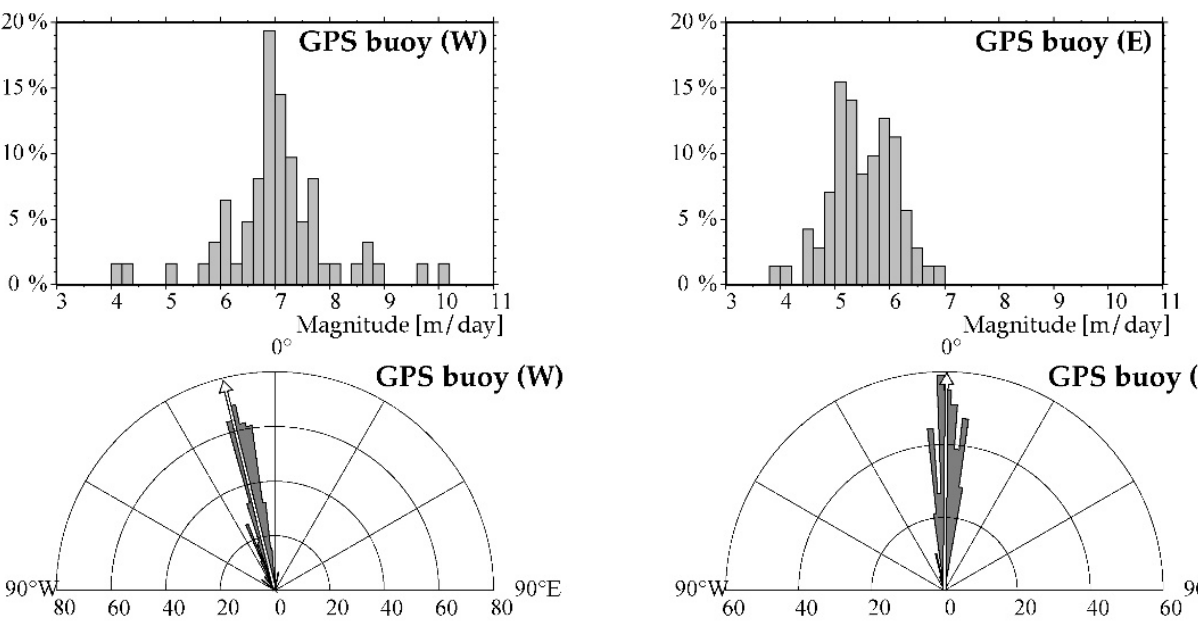

$0^{\circ}$

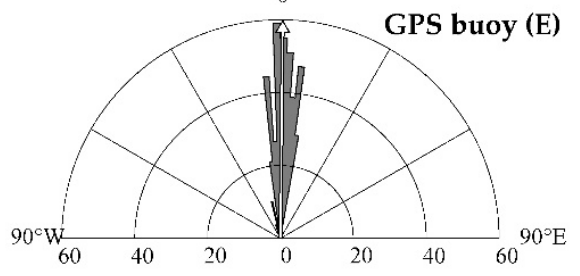

(d)
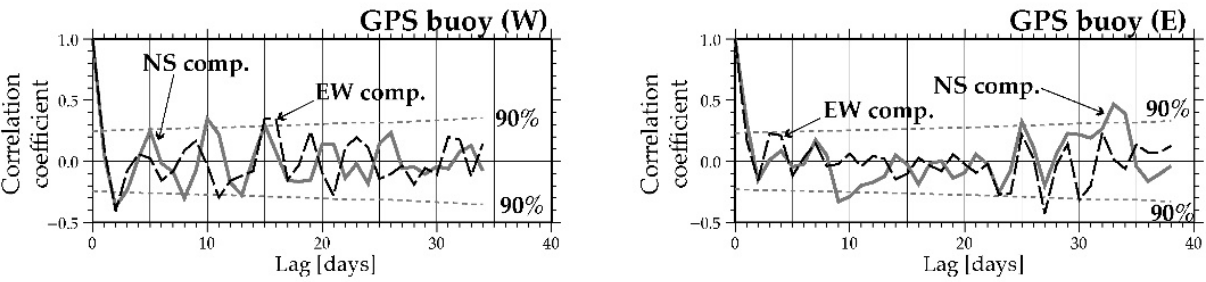

(e)
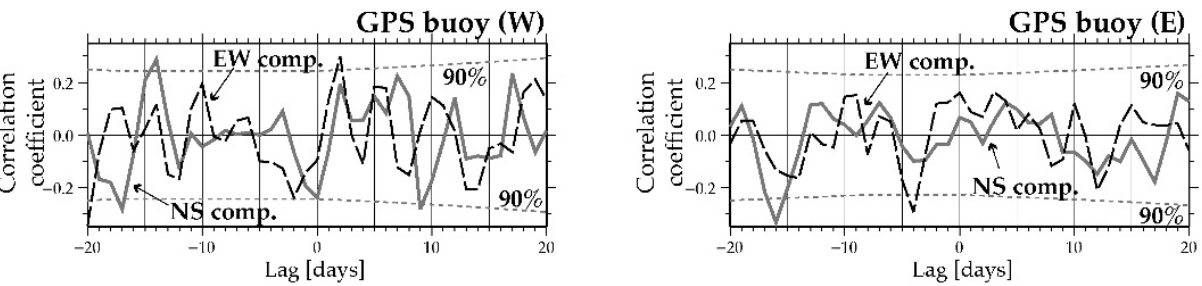

Fig. 5. Short-term velocity vectors derived from a 72-hour sliding window analysis. (a) Phasor plot of short-term velocity vectors with an exaggerated error interval. Black rectangles show periods when the daily mean wind velocity recorded at Syowa Station exceeded $10 \mathrm{~m} / \mathrm{s}$. (b) Histograms showing the magnitude of velocity vectors. (c) Rose diagrams showing the azimuth of velocity vectors. (d) Autocorrelation analysis of both north-south (NS) and east-west (EW) components of the short-term velocity vectors. The dotted lines indicate $90 \%$ confidence intervals. (e) Cross-correlations of each NS and EW component of the short-term velocity vectors with the daily mean wind velocity data recorded at Syowa Station.

with the Shirase Glacier drifted predominantly downstream (north), but in slightly different directions on its east and west sides. Horizontal distances from the origin (Fig. 4(c)) were also estimated from these linear relationships. By fitting Eq. (1), the flow velocities of the east and west sides were estimated from the slope of the linear regression for each GPS buoy, $b_{\mathrm{GPS}(\mathrm{E})}$ and $b_{\mathrm{GPS}(\mathrm{W})}$, as $5.779 \pm 0.004$ and $7.005 \pm 0.006 \mathrm{~m} /$ day, respectively. These values are equivalent to 2.11 and $2.59 \mathrm{~km} /$ year, respectively, assuming no seasonal variations. These mean annual velocities, based on our GPS data, are generally consistent with those estimated from aerial photographs (Fujii, 1981), InSAR (Pattyn and
Derauw, 2002; Rignot, 2002), and SAR image correlation (Nakamura et al., 2010).

\section{Discussion}

\subsection{Variations in flow direction and speed}

The GPS data demonstrate that the velocity of the ice flow in the floating ice tongue region was higher on the west side than the east side, as shown by Fujii (1981) and Nakamura et al. (2007a, 2010). In addition, Nakamura et al. (2007a) reported that the flow direction turned with distance from the grounding line in the downstream region from $\mathrm{N} 48^{\circ} \mathrm{W}$ to $\mathrm{N} 2{ }^{\circ} \mathrm{E}$ based on SAR image correlation. 
The flow directions measured with GPS buoys (E) and (W) support those estimates. Regarding both the magnitude and direction (azimuth) of the velocity, the velocity vectors of GPS buoys (E) and (W) are approximately consistent with the horizontal distribution of the flow velocity vectors of the Shirase Glacier in 2007, estimated from SAR image correlation (Nakamura et al., 2010). Therefore, the averaged velocity vectors obtained from the two GPS buoys between February and April 2010 represent a plausible ice flow pattern for the downstream region of the Shirase Glacier.

\subsection{Short-term variations}

The relatively fast flow of the ice stream enabled us to analyze short-term fluctuations in the velocity vectors from the 30-minute GPS location datasets, despite the low accuracy of the single-frequency code GPS. We found that the linear trend became evident over time periods longer than 3 days. The slope coefficients of the linear regression for the EW and NS components, $b_{\mathrm{EW}}$ and $b_{\mathrm{NS}}$, respectively, were derived for each 72-hour sliding window shifted every 24 hours. The obtained short-term velocity vectors of GPS buoys (E) and (W) demonstrated departures in their magnitude and azimuth from the averaged ice flow (Fig. 5(a)). For example, their magnitude and azimuth ranged from 3.82 to $7.71 \mathrm{~m} /$ day and $-18.1^{\circ}$ to $31.7^{\circ}$, respectively, for GPS buoy (E), while they varied between 4.07 to $11.17 \mathrm{~m} /$ day and $-51.9^{\circ}$ to $10.6^{\circ}$, respectively, for GPS buoy (W). In contrast, the standard deviation (at the $99 \%$ confidence level based on the t-distribution) of the magnitude and direction of each velocity vector ranged from \pm 0.13 to $\pm 0.21 \mathrm{~m} /$ day and $\pm 1.0^{\circ}$ to $\pm 2.2^{\circ}$, respectively, for GPS buoy (E), and \pm 0.12 to $\pm 0.33 \mathrm{~m} /$ day and $\pm 0.9^{\circ}$ to $\pm 3.2^{\circ}$, respectively, for GPS buoy (W). These values confirm that fluctuations around the average flow velocity vectors did occur in the short-term velocity vectors. Moreover, histograms of the magnitude, and rose diagrams of the direction, of the shortterm velocity vectors statistically demonstrate that individual vectors vary from the mean values in both their magnitude and direction (Figs. 5(b, c)).

After 6 March, the short-term velocity vectors of GPS buoy (W) became irregular and its standard deviations increased. At the $99 \%$ confidence level, the magnitudes and azimuths of the short-term velocity vectors were in the ranges 6.08 to $7.63 \mathrm{~m} /$ day $( \pm 0.12$ to $\pm 0.17 \mathrm{~m} /$ day $)$ and $-17.9^{\circ}$ to $-9.2^{\circ}\left( \pm 0.9^{\circ}\right.$ to $\left.\pm 1.3^{\circ}\right)$, respectively, before 6 March, but 4.07 to $11.17 \mathrm{~m} /$ day $( \pm 0.17$ to $\pm 0.33 \mathrm{~m} /$ day $)$ and $-51.9^{\circ}$ to $10.6^{\circ}\left( \pm 1.3^{\circ}\right.$ to $\left.\pm 3.2^{\circ}\right)$, respectively, after 6 March. This increased variability may have been caused by a degradation in the accuracy of the GPS due to snow cover. Obvious diurnal variations associated with a solar power generation appeared in the battery power data from both GPS buoys (Fig. 4(d)). However, the diurnal variations in the battery level of GPS buoy (W) were no longer evident following a blizzard on 5 March, although solar radiation recorded at Syowa Station, about $150 \mathrm{~km}$ north of the Shirase Glacier (Fig. 2), during 7-18 March remained at the same level as before 5 March. The diurnal variations in the battery level of GPS buoy (E) continued until 14 March. Although GPS buoy (W) was located at a higher latitude than GPS buoy (E), the number of daylight hours were almost the same because these dates were before the autumn equinox. Therefore, GPS buoy (W) may have been covered by snow, which attenuated the intensity of the received GPS signal and caused the instantaneous locations to be more widely dispersed around the average values.

\subsection{Measurement precision}

It is necessary to consider the precision of the ice flow measurements derived from the single-frequency GPS. The nominal error of this GPS is about $10 \mathrm{~m}$. Deviations of the instantaneous positions from the linear regression line were distributed elliptically, with the $99 \%$ confidence intervals (corresponding to standard errors (SEs) multiplied by 2.58 in the case of the zero mean) for the EW and NS components being $\pm 0.148 \mathrm{~m}$ and $\pm 0.202 \mathrm{~m}$ for GPS buoy (E), and $\pm 0.325 \mathrm{~m}$ and $\pm 0.337 \mathrm{~m}$ for GPS buoy (W), respectively, (Fig. 3, bottom). These SEs indicate a deviation from the steady linear movement, in addition to the GPS errors. In contrast, the SEs at the $99 \%$ confidence level derived from the residuals of the sliding window analysis were $\pm 0.125 \mathrm{~m}(\mathrm{EW})$ and $\pm 0.191 \mathrm{~m}(\mathrm{NS})$ for GPS buoy (E), and $\pm 0.308 \mathrm{~m}(\mathrm{EW})$ and $\pm 0.328 \mathrm{~m}$ (NS) for GPS buoy (W). This slight improvement in the SEs of the residuals from the sliding window analysis compared with the deviations from the 3-month mean flow suggests that the deviations from the mean flow during the monitoring period were real. The large SEs from GPS buoy (W) arose from the irregular variations after 6 March. For instance, the SEs before 6 March were $\pm 0.205 \mathrm{~m}$ for both the EW and NS components $(n=1386)$, while those after 6 March were $\pm 0.532 \mathrm{~m}$ $(\mathrm{EW})$ and $\pm 0.568 \mathrm{~m}(\mathrm{NS})(n=1723)$. As the SEs before 6 March were equivalent to those of GPS buoy (E), we conclude that the single-frequency code GPS is able to measure the fast ice flow to a precision of better than $0.2 \mathrm{~m} / \mathrm{s}$.

The short-term velocity vectors derived from GPS buoys (E) and (W) (Fig. 5(a)) appear to show a periodic fluctuation in their magnitude and azimuth. Autocorrelation analysis of the NS and EW components of the short-term velocity vectors shows that the NS component of GPS buoy (W), and the EW component of GPS buoy (E), have periods of 10 and 3 days, respectively (Fig. 5(d)). Figure 5(a) shows that the fluctuations in the magnitude and azimuth of these short-term velocity vectors occurred when the wind speed exceeded $10 \mathrm{~m} / \mathrm{s}$ at Syowa Station. The NS component of GPS buoy (W) showed the negative correlation, with a delay of 0 and 9 days and exceeding $90 \%$ confidence, with the wind speeds at Syowa Station, which had a 9-day period estimated from autocorrelation. Its EW component also had significant positive correlation with a delay of 2 days with the wind speeds. These results suggest that the single-frequency GPS has the potential to detect short-term fluctuations in the flow of the floating ice tongue with periods of 3-10 days.

Assuming that the power supply unit, which consists of the battery and the solar panel, is heavily reinforced, and that the GPS antenna and solar panel are placed at a sufficient height to prevent them from being covered with snow, we suggest that measuring the flow rate and direction of an ice stream over weekly, to seasonal, timescales is possible with the type of low-cost single-frequency GPS equipment used here. In future, we plan to install a network of these modified low-cost GPS buoys to enable the direct, de- 
tailed, and long-term monitoring of ice flow at the Shirase Glacier. The data from this monitoring network will improve our understanding of the ice flow, particularly when combined with comprehensive ice motion estimates derived from SAR analyses. A time-lapse video of the ice flow of the Shirase Glacier, which had been recorded by staffs of the Japan Broadcasting Corporation in 2003, showed an intermittent motion of a few meters over periods of several hours. In addition, we installed a dual-frequency GPS, without the satellite communication system, on the floating ice tongue of the Shirase Glacier $\left(38.7111^{\circ} \mathrm{E}, 70.0404^{\circ} \mathrm{S}\right)$ between 28 December, 2011, and 14 February, 2012. The intermittent motion of the ice flow was recorded, as well as the ocean tide, by applying precise point positioning analysis (in prep.), and it seems that very rapid ice motion related to the tide (Bindschadler et al., 2003) may also occur in the Shirase Glacier. To detect such motion, we also plan to install several dual-frequency GPS systems, simultaneously with the multiple low-cost GPS buoys, in addition to making surface synoptic observations near the Shirase Glacier.

\section{Summary}

The ice flow of the Shirase Glacier floating ice tongue was directly measured using two buoys, each equipped with a low-cost single-frequency GPS unit and an Iridium satellite communication system. The GPS buoys were installed on the east and west sides of the floating ice tongue on 5 February, 2010. The instantaneous GPS locations (longitude and latitude) were obtained every 30 minutes between 07:30 UT on 5 February and 00:30 UT on 24 April for the eastern GPS buoy, and 07:00 UT on 5 February and 06:00 UT on 15 April for the western GPS buoy. By fitting a straight line to the 30-minute location data using the least squares method, we calculated the average horizontal velocity vector of the ice flow. Its magnitude and azimuth were estimated as $5.779 \pm 0.004 \mathrm{~m} /$ day, $\mathrm{N} 1.4^{\circ} \mathrm{E} \pm 0.5^{\circ}$, respectively, for the eastern buoy, and $7.005 \pm 0.006 \mathrm{~m} /$ day and $\mathrm{N} 13.1^{\circ} \mathrm{W} \pm 0.6^{\circ}$, respectively, for the western buoy. The differing magnitude and azimuth of the ice flow to the east and west of the glacier recorded here agree with results based on SAR image correlation analysis (Nakamura et al., 2007a). The mean annual velocities (assuming no seasonal variations) were 2.11 and $2.59 \mathrm{~km} /$ year, for the east and west sections, respectively. These values also agree approximately with recent SAR ice flow estimates of the downstream region (Nakamura et al., 2010).

The short-term velocity vectors were derived from the least squares fitting of a line to the data extracted by a 72 hour sliding window shifted every 24 hours. The magnitude and azimuth of these ice flow vectors varied around their mean values with a period of about $3-10$ days. These results demonstrate that a single-frequency GPS is able to detect short-term fluctuations in the flow of the floating ice tongue that have periods of less than 10 days.

Acknowledgments. The GPS measurements were completed with the cooperation of the $51^{\text {st }}$ Japanese Antarctic Research Expedition led by Y. Motoyoshi. The authors acknowledge F. Pattyn and Y. Ohta for their careful reviews of the manuscript. The time-lapse video of the ice flow of Shirase Glacier was filmed and archived by the Japan Broadcasting Corporation (NHK). The surface synoptic data observed at Syowa Station are available from the web site of the Japan Meteorological Agency (http://www.jma.go.jp). The production of this paper was supported by an NIPR publication subsidy.

\section{References}

Bindschadler, R. A., M. A. King, R. B. Alley, S. Anandakrishnan, and L. Padman, Tidally controlled stick-slip discharge of a west Antarctic ice stream, Science, 301, 1087-1089, 2003.

Chen, J. L., C. R. Wilson, and B. D. Tapley, Satellite gravity measurements confirm accelerated melting of Greenland ice sheet, Science, 313, 19581960, 2006.

Fujii, Y., Aerophotographic interpretation of surface features and estimation of ice discharge at the outlet of the Shirase drainage basin, Antarctica, Antarct. Rec., 72, 1-15, 1981.

Mae, S. and R. Naruse, Possible causes of ice sheet thinning in the Mizuho Plateau, Nature, 273, 291-293, 1978.

Moriwaki, K. and Y. Yoshida, Bathymetric chart of Lützow-Holm Bay, 1/250000, Spec. Map Ser. Natl. Inst. Polar Res., 4b, 2002.

Nakamura, K., K. Doi, and K. Shibuya, Why is Shirase Glacier turning its flow direction eastward?, Polar Sci., 1, 63-71, 2007a.

Nakamura, K., K. Doi, and K. Shibuya, Estimation of seasonal changes in the flow of Shirase Glacier using JERS-1/SAR image correlation, Polar Sci., 1, 71-83, 2007b.

Nakamura, K., K. Doi, and K. Shibuya, Fluctuations in the flow velocity of the Antarctic Shirase Glacier over an 11-year period, Polar Sci., 4, 443-455, 2010.

Pattyn, F. and D. Derauw, Ice-dynamic conditions of Shirase Glacier, Antarctica, inferred from ERS SAR interferometry, J. Glaciol., 163, 559-565, 2002.

Rignot, E., Mass balance of East Antarctic glaciers and ice shelves from satellite data, Ann. Glaciol., 34, 217-227, 2002.

Rignot, E. et al., Recent Antarctic ice mass loss from radar interferometry and regional climate modeling, Nat. Geosci., 1, 106-110, 2008.

Rignot, E., J. Mouginot, and B. Scheuchl, Ice flow of the Antarctic ice sheet, Science, 333, 1427-1430, 2011a.

Rignot, E., I. Velicogna, M. R. van den Broeke, A. Monaghan, and J. Lenaerts, Acceleration of the contribution of the Greenland and Antarctic ice sheets to sea level rise, Geophys. Res. Lett., 38, L05503, 2011 b.

Shepherd, A., D. Wingham, D. Wallis, K. Giles, S. Laxon, and A. V. Sundal, Recent loss of floating ice and the consequent sea level contribution, Geophys. Res. Lett., 37, L13503, 2010.

Velicogna, I. and J. Wahr, Measurements of time-variable gravity show mass loss in Antarctica, Science, 311, 1754-1756, 2006.

Y. Aoyama (e-mail: aoyama@nipr.ac.jp), K. Doi, K. Shibuya, H. Ohta, and I. Tsuwa 